\title{
LA LEGISLACION URGENTE Y LA DE PRESUPUESTOS PARA EL AÑO 2002. NOVEDADES INTRODUCIDAS EN EL AMBITO DE LAS PRESTACIONES ECONOMICAS DE LA SEGURIDAD SOCIAL
}

\author{
Fernando Manrique López \\ Catedrático de Derecho del Trabajo de la Universidad de Deusto
}

Una de las tareas más complejas e incomodas que se plantea cada año a quien opera con las normas del Derecho de la Seguridad Social, viene a ser la localización de las novedades, que se introducen a través de la Ley de Medidas Urgentes en el campo social y de las Leyes de Presupuestos (Verdaderas Leyes Ómnibus), para lo cual viene a resultar indispensable estar al trabajo detallado y minucioso que se lleva a cabo habitualmente desde el seno de la Administración de la Seguridad Social, merced al cual pueden resaltarse, tal y como dicha Administración expone, las verdaderas novedades legislativas, sin temor a incurrir en un error.

El presente trabajo tiene como misión recoger tales novedades, tomando como base el mencionado meritorio trabajo de la propia Administración, procurando así que tenga la difusión que una materia tan trascendente posee en la realidad jurídica actual.

\section{Síntesis de las novedades normativas introducidas con fecha 1 de enero de 2002}

Con efectos de 1 de enero de 2002, se han promulgado diferentes disposiciones que, de forma directa o indirecta, afectan al régimen jurídico o a la gestión de las prestaciones económicas de la Seguridad Social, y a la responsabilidad del Instituto Nacional de la Seguridad Social.

Las modificaciones, normativas son, en síntesis, las siguientes: 


\section{Ley 23/2001, de 27 de diciembre, de Presupuestos Generales del Estado para 2002}

A través de la misma, se regula la revalorización de las pensiones de la Seguridad Social, cuya aplicación y desarrollo se contiene en el Real Decreto 1.464/2001, de 27 de diciembre, sobre revalorización de las pensiones de la Seguridad Social.

2. Ley 24/2001, de 27 de diciembre, de medidas fiscales, administrativas $y$ del orden social (LAC)

En dicho texto legislativo, se contienen diferentes disposiciones que afecta, directa o indirectamente, a las prestaciones económicas de la Seguridad Social. Entre las mismas, son de destacar las siguientes:

a) Preceptos Que afectan a la PRESTACión De inCAPACIDAd temporal

Son cuatro las modificaciones que afectan al régimen jurídico de la prestación económica de la Seguridad Social por incapacidad temporal:

- La extinción de la prestación, en los casos en que el beneficiario de la misma no acuda, sin causa justificada, a los reconocimientos médicos ordenados por la Dirección Provincial del INSS, a través de sus Servicios Médicos (nueva redacción del artículo 131 bis LGSS, en la redacción incorporada por el artículo 34. Cuatro. LAC).

La nueva redacción del artículo 131.bis.1 LGSS suprime el anterior párrafo segundo de dicho apartado, relativo a la expedición, por parte de los servicios médicos del Instituto Nacional de la Seguridad Social, de altas en los procesos de IT, a los exclusivos efectos de las prestaciones económicas del sistema de la Seguridad Social.

- Nueva regulación de la prestación de IT, cuando la misma continúa tras la extinción de la relación laboral, así como la correspondiente a los procesos de IT que se causen, estando el interesado en la situación de desempleo (nueva redacción del artículo 222 LGSS, en la redacción que incorpora el artículo 34.Diez.LAC).

- El establecimiento, como sanción, de la extinción de la prestación de incapacidad temporal, en los casos en que el beneficiario de la misma cometa la infracción, tipificada como grave - artículo 25 LISOS - de no acudir, sin causa justificada, a los reconocimientos médicos ordenados por la Dirección Provincial del Instituto 
Nacional de la Seguridad Social, a través de sus Servicios Médicos (nueva redacción del artículo 47.1.b) de la Ley de Infracciones y Sanciones del Orden Social, texto refundido aprobado por Real Decreto-Legislativo 5/2000, de 4 de agosto - LISOS—, a través del artículo 34.Uno.LAC).

- Por último, el mantenimiento de la obligación de cotizar (con su efecto en las prestaciones futuras) en los casos de alta con propuesta de incapacidad permanente, cuando posteriormente la prestación no es reconocida. (Incorporación de un nuevo párrafo, en el artículo 131.bis.3.LGSS, a través del artículo 34.Cinco.LAC).

\section{b) JUBILACIÓN PARCIAL}

El artículo 34.Seis.LAC da nueva redacción al artículo 166 LGSS, en orden a adecuar la regulación jurídica de esta prestación de la Seguridad Social, a las modificaciones introducidas, en el artículo 12.6 del Estatuto de los Trabajadores -ET - por la Ley 12/2001, de 9 de julio, de medidas urgentes de reforma del mercado de trabajo y mejora de su calidad.

La regulación contenida en la LAC se completa con el artículo 2 del Real Decreto-Ley 16/2001, de 27 de diciembre, por el que se establece un sistema gradual y flexible de jubilación, mediante el que se difiere a disposición reglamentaria la regulación jurídica de la jubilación parcial, en el ámbito de la Seguridad Social.

\section{c) Prestaciones de Muerte y SUPerviVencia}

Dos son las modificaciones que, en el ámbito de las prestaciones de muerte y supervivencia, se recogen en la LAC:

- La modificación del apartado 3 del artículo 174 LGSS (a través del artículo 34.Siete.LAC), en el que, manteniendo como causa de extinción el nuevo matrimonio del pensionista, sin embargo prevé su mantenimiento en los supuestos que se establezcan reglamentariamente.

- La ampliación hasta los 22 años (24 años, en caso de inexistencia de ambos padres) de los límites de edad para percibir la pensión de orfandad, en los casos en que el huérfano no trabaje o, cuando haciéndolo, los ingresos derivados de la actividad no superen, en cuantía anual, el 75\% del importe anual del salario mínimo interprofesional. (Nueva redacción del artículo 175.2 LGSS por el artículo 34.Ocho.LAC). 
Las previsiones legales se completan con el Real Decreto 1465/2001, de 27 de diciembre, por el que se modifica parcialmente el régimen jurídico de las prestaciones de muerte y supervivencia (RDMS), cuyo contenido se analiza en el punto 3 .

\section{d) Responsabilidad EN ORDEN a LAS PRESTACIONES}

El artículo 34.Tres. da nueva redacción al artículo 126 LGSS (mediante la incorporación de tres nuevos párrafos en el apartado $3 .^{\circ}$ y la adicción de un nuevo apartado $4 .^{\mathrm{a}}$ ), cuyos puntos más importantes son los siguientes:

- De una parte, establece la competencia de la Entidad Gestora para declarar, en vía administrativa, la responsabilidad en orden a las prestaciones, cualquiera que sea la prestación de que se trate, así como la Entidad que, en su caso, deba anticipar el importe de la prestación o constituir el correspondiente capital coste.

- Se limita el anticipo de las prestaciones (en los casos y en las situaciones en que corresponda el mismo) a una cuantía máxima de 2,5 veces la cuantía que, en cada momento, esté fijada para el salario mínimo interprofesional.

- En ningún caso, procede la acción contra el Instituto Nacional de la Seguridad Social (en su función de garantía) por la Mutua o por la Entidad que tenga el correspondiente derecho, mientras no se haya declarado, en vía administrativa o judicial, la insolvencia, provisional o definitiva, del empresario responsable principal.

\section{e) AdOPCIÓN DE MEDIDAS CAUTELARES}

El artículo 36 LAC procede a la incorporación de una nueva Disposición Adicional en la LGSS - la 17. ${ }^{\mathrm{a}}$ bis-, mediante la que se posibilita que la Entidad responsable de las prestaciones económicas pueda suspender, ad cautelam, el abono de las mismas, en caso de incumplimiento, por parte de los beneficiarios o causantes de las mismas, de presentar, en los plazos establecidos, las declaraciones preceptivas o documentos, antecedentes, justificantes o datos que no obren en la Entidad, y siempre que sean requeridos para ello, siempre que unos y otros puedan afectar a la conservación del derecho.

La suspensión se mantendrá hasta que se justifique que se siguen manteniendo los requisitos legales, imprescindibles para el mantenimiento del derecho.

La suspensión prevista en la Adicional 17. ${ }^{\mathrm{a}}$ bis, se entiende sin perjuicio de la posibilidad que tiene la Gestora, en base al artículo 47.4, 
LISOS, de suspender cautelarmente el abono de una prestación, cuando se haya iniciado un expediente sancionador y la infracción cometida afecte al mantenimiento de los requisitos necesarios para la conservación del derecho.

\section{f) Normas PROCEDimentales}

La LAC contiene dos preceptos básico, que afectan a las normas procedimentales en el ámbito de la gestión de las prestaciones de Seguridad Social, como son:

- El artículo 34.Once. incorpora en la LGSS una nueva Disposición Adicional - la 25. a - a través de la cual se establecen normas de procedimiento en la Seguridad Social.

La nueva regulación no introduce especiales novedades sobre las reglas que se venía aplicando, salvo la de que en la propia Ley General de la Seguridad Social se prevé expresamente cuál es la norma de procedimiento (que ya se deducía de los artículos 1 y 2 de la Ley 30/1992, de 26 de noviembre, de Régimen Jurídico y de Procedimiento Administrativo Común - LRJPC-).

Los puntos más significativos de la nueva Adicional son los siguientes:

- La afirmación de que la tramitación de las prestaciones y demás actos en materia de Seguridad Social, que no tengan carácter recaudatorio o sancionador, se ajustan a lo establecido en la LRJPC.

- La impugnación de tales actos, así como la revisión de oficio de los mismos, se regulará por lo establecido en la Ley de Procedimiento Laboral.

- En los procedimientos iniciados a instancia del interesado, una vez transcurrido el plazo máximo para la resolución y su notificación, se entenderá desestimada la solicitud por silencio negativo.

- No obstante, en los procedimientos relativos a la inscripción de empresas, y a la afiliación, altas, bajas y variaciones de datos, iniciados a solicitud de los interesados, así como los de convenio especial, la falta de resolución en plazo de la correspondiente solicitud, tendrá como efecto la estimación de la misma, por silencio administrativo.

— La nueva redacción dada al artículo 71 LPL, respecto a la impugnación de los actos de la Seguridad Social (a través del ar- 
tículo 42 LAC) la cual, frente a la regulación anterior, presenta las siguientes novedades:

- Se establece expresamente la necesidad de que, en todo caso y como presupuesto para la impugnación judicial de los actos de la Seguridad Social, se presente reclamación previa.

- No obstante, en determinados supuestos se prevé la eventualidad de que, contra resoluciones expresas o presuntas de las Mutuas, pueda formalizarse reclamación previa ante la Entidad Gestora, en los supuestos en que exista competencia sobre la materia.

- En los procedimientos iniciados a instancia de parte, la reclamación previa ha de presentarse, ante el Organo que dictó la resolución, en el plazo de 30 días desde la notificación de la misma, si es expresa o desde la fecha en que, según el procedimiento de que se trate, deba entenderse denegada por silencio administrativo.

- Si en el reconocimiento inicial o en la modificación del derecho, la Entidad ha de actuar de oficio, si no se produce el acto o la resolución, el interesado puede solicitar que se dicte, teniendo la petición el valor de reclamación previa.

- Como novedad frente a la indeterminación anterior, el artículo 71.4.LPL establece que, en todos los casos, la reclamación previa deberá ser contestada en el plazo de 45 días. En caso contrario, se entenderá desestimada la reclamación por silencio administrativo.

\section{g) OtRas nOvedades}

Por último, el artículo 37 LAC procede a suprimir la obligación empresarial de llevar el Libro de Matrícula. Por ello, también con efecto de 1 de enero de 2002, queda suprimido el artículo 101 LGSS, así como la tipificación como infracción social, el hecho de no llevar dicho Libro (por lo que se deroga el artículo 22.3.LISOS).

3. Real Decreto $1.465 / 2001$, de 27 de diciembre, de modificación parcial del régimen jurídico de las prestaciones de muerte y supervivencia. (RDMS)

El RDMS incorpora determinadas medidas relacionadas con las prestaciones de muerte y supervivencia, de modo siguiente: 
a) Pensión de ViUdedad

Las novedades que incorpora el RDMS en relación con la pensión de viudedad son las siguientes:

- Cuantía de la pensión de viudedad. (Artículo 1 RDMS):

- Con carácter general, y desde el 1 de enero de 2002, la cuantía de la pensión de viudedad pasa a ser el $46 \%$ de la correspondiente base reguladora.

Respecto de las pensiones causadas, la nueva cuantía de la pensión se aplicará de oficio.

- Cuando los ingresos del pensionista no superen una determinada cuantía, la pensión constituye, al menos, el 50\% de los ingresos y aquél tiene cargas familiares, la cuantía de la pensión es el equivalente al $70 \%$ de la base reguladora.

La nueva cuantía de la pensión se aplicará, previa solicitud del interesado. La nueva cuantía de la pensión tiene efectos desde el 1 de enero de 2002, siempre que se solicite antes del 1 de abril de 2002; en otro caso, la nueva cuantía tiene una retroactividad máxima de tres meses.

—Extinción de la pensión de viudedad. (Artículo 2 RDMS):

- Se sigue manteniendo, como regla general, que el nuevo matrimonio del pensionista de viudedad extingue la pensión de viudedad, salvo en los supuestos que se indican en el punto siguiente.

- El matrimonio del pensionista no extingue la pensión de viudedad, cuando concurren, de forma conjunta, los siguientes requisitos:

- Que el pensionista que va a contraer matrimonio tenga al menos, 61 años, o tenga reconocida también una pensión de incapacidad permanente (en los grados de incapacidad absoluta o gran invalidez) o se acredite un grado de minusvalía igual o superior al $65 \%$.

- Que la pensión de viudedad constituya el 75\% del total de los ingresos del pensionista.

- Que los ingresos del nuevo matrimonio no superen dos veces el salario mínimo. En caso contrario, y cumplidos los dos requisitos anteriores, la cuantía de la pensión de viudedad se minora para que no se exceda del límite indicado.

- En todo caso, desaparece la indemnización de 24 mensualidades por nuevo matrimonio del pensionista. 
- De igual modo, desaparece del ordenamiento jurídico de la Seguridad Social, y como causa de extinción de la pensión de viudedad (que desde hace tiempo el INSS ya no aplicaba) la observancia de una conducta deshonesta, así como la de profesar estado religioso.

b) PEnsión de ORFANDAD (artículo 3 RDMS)

-En aplicación de la LAC, el RDMS amplia los límites para percibir las pensiones de orfandad, más allá de los 18 años.

- Los nuevos límites de edad, para seguir percibiendo la pensión de orfandad, no solo se aplican a las pensiones de orfandad, sino también a las pensiones que se extinguieron antes de $1 .^{\circ}$ de enero de 2002, siempre que los beneficiarios cumplan los requisitos de edad y de falta de ingresos.

- Se modifican las causas de extinción de la pensión de orfandad, suprimiendo la de profesar estado religioso y la de conducta deshonesta.

\section{c) Prestaciones en faVor de familiares (artículos 4 y 5 RDMS)}

- Los nuevos límites para seguir percibiendo la pensión de orfandad (22 años) se aplican de igual modo a las pensiones a favor de los nietos y hermanos del causante, siempre que el beneficiario no trabaje o, cuando haciéndolo, los ingresos anuales del trabajo no superen el $75 \%$ del importe anual del SMI.

Al igual que sucede con las pensiones de orfandad, los nuevos límites de edad también se aplican a las pensiones extinguidas del 1 de enero de 2002, siempre que los beneficiarios cumplan los requisitos de edad y menores ingresos.

- Se modifican las causas de extinción de las prestaciones a favor de familiares, a fin de ajustarlas a las establecidas para la pensión de orfandad.

- Se fija como límite para el acceso al subsidio temporal en favor de familiares, la edad de 22 años, a fin de acomodarlo a la edad de extinción de la pensión a favor de nietos o hermanos. (Artículo 5).

4. Real Decreto-Ley 16/2001, de 27 de diciembre, de medidas para el establecimiento de un sistema de jubilación gradual y flexible. $(R D L J)$

Son múltiples las modificaciones que el RDLJ contiene en el ámbito de las pensiones de jubilación e incapacidad permanente, como a continuación se indican: 


\section{a) JUBILACIÓN ANTICIPADA POR DERECHO TRANSITORIO}

En esta situación, el artículo 4 RDLJ establece la novedad de modificar los coeficientes reductores (por cada año que le falte al interesado para cumplir los 65 años) en los casos en que el acceso a la pensión (o la extinción del contrato de trabajo anterior) no sea debida a causa imputable al trabajador, en los términos previstos en la Disposición Transitoria Segunda del Real Decreto 1.647/1997, de 31 de octubre.

\section{b) Nuevos MECANISMos DE JUbILACión ANTICIPADA}

El artículo 3 RDLJ establece un nuevo sistema de jubilación anticipada, aunque el trabajador no tenga acreditada la condición de mutualista, siempre que reúna los requisitos previstos en dicho artículo.

Reconocido el derecho a la pensión, la misma es objeto de minoración aplicando unos coeficientes reductores, por cada año que al trabajador le falte, en el momento del hecho causante, para cumplir 65 años, coeficientes que varían en función del período de cotización acreditado.

\section{c) Compatibilidad de LA PENSIÓN DE JUBilación}

El artículo 1 RDLJ procede a modificar el artículo 165 LGSS, incorporado un segundo párrafo a su apartado primero, que supone una excepción al principio general de incompatibilidad entre el percibo de la pensión de jubilación y la realización de actividades que den lugar a su inclusión en cualquiera de los Regímenes que integran el sistema de la Seguridad Social.

A tenor de la nueva disposición legal, las personas que hayan accedido a la pensión de jubilación podrán compatibilizar su percibo con la realización de un trabajo a tiempo parcial. En estos casos, se minorará el percibo de la pensión de jubilación en proporción inversa a la reducción aplicable a la jornada de trabajo, en relación a la de un trabajador a tiempo completo comparable.

\section{d) Subsidio Por Desempleo Para trabajadores mayores de 52 aÑos}

El RDLJ (artículo 5) modifica el artículo 216.3 LGSS, en relación con la extensión máxima de subsidio asistencial por desempleo, a favor de trabajadores con 52 o más años, que reúnan todos los requisitos, salvo la edad, para acceder a la pensión de jubilación.

En la regulación anterior al 1 de enero de 2002, dicho subsidio se extinguía en el momento en el que el trabajador alcanzase la edad que 
le permitiese acceder a la pensión contributiva de jubilación, en cualquiera de sus modalidades, de tal forma que, por ejemplo, si el trabajador tenía la condición de mutualista, el subsidio se extinguía en la fecha de cumplimiento, por parte del trabajador, de los 60 años.

La nueva regulación contenida en el citado artículo 216.3 LGSS prevé que el subsidio se extienda, como máximo, hasta que el trabajador alcance la edad ordinaria que se exija, en su caso, para causar derecho a la pensión de jubilación.

\section{e) Cuantía de la Pensión de Jubilación}

Hasta el 1 de enero de 2002, la cuantía de la pensión de jubilación tenía, como límite máximo, el $100 \%$ de la respectiva base reguladora, sin perjuicio de que, una vez calculado dicho importe, la pensión tuviese que ser reducida por la aplicación del tope máximo de percepción de pensión pública, vigente en cada momento.

El artículo 10 RDLJ establece una modificación en la materia señalada, a través de la inclusión de un nuevo apartado 2 en el artículo 163 LGSS, el cual permite la aplicación de un porcentaje superior al 100\% a la base reguladora, en los supuestos en que el acceso a la jubilación se produzca con posterioridad al cumplimiento de los 65 años.

En tal sentido, el nuevo artículo 163.2 LGSS prevé que, en los supuestos en que se acceda a la pensión de jubilación a una edad superior a los 65 años, el porcentaje aplicable a la respectiva base reguladora será el resultado de sumar al $100 \%$, un $2 \%$ adicional, por cada año completo que, en la fecha del hecho causante de la pensión, se haya cotizado desde el cumplimiento de los 65 años, siempre que en dicho momento el interesado tuviese acreditados 35 años de cotización.

\section{f) Modificaciones en El ÁMBito De INCAPACIDAD PERMANENTE}

La Ley 24/1997, de 15 de julio, modificó la regulación de la incapacidad permanente, en el sentido de que no se pudiese acceder a la pensión, cualquiera que fuese la contingencia de la que derive, si el interesado, en el momento del hecho causante, había cumplido los 65 años de edad, siempre que aquél reuniese, en la indicada fecha, todos los requisitos para acceder a la pensión de jubilación.

Respecto a esta cuestión, las modificaciones introducidas por el RDLJ (artículos 8 y 9) son las siguientes:

— La limitación en el acceso a la pensión de incapacidad permanente, una vez que el interesado haya cumplido 65 años, sola- 
mente operará respecto a la pensiones derivadas de contingencias comunes. Por ello, si la causa de la incapacidad deriva de un accidente de trabajo o de una enfermedad profesional, se podrá acceder a la respectiva pensión, siempre que se acredite el grado correspondiente y se reúnan los demás requisitos establecidos.

- Cuando la causa de incapacidad permanente derive de una contingencia común, seguirá limitado el acceso a la pensión de incapacidad permanente, cumplidos por el trabajador los 65 años de edad, si el interesado reúne los requisitos de acceso a la pensión de jubilación. En este supuesto, y conforme a la Circular 3/98, se deberá notificar al interesado el derecho que le asiste de poder solicitar la pensión de jubilación.

- $\mathrm{Si}$, por el contrario, acredita un determinado grado de incapacidad permanente, y el interesado no reúne requisitos para la pensión de jubilación, el mismo accederá a la pensión de incapacidad permanente, si bien la cuantía de la misma será el equivalente a aplicar sobre la respectiva base reguladora el porcentaje que corresponda al período mínimo de cotización en orden a la determinación de la pensión de jubilación, es decir, el 50\%.

\section{g) LIMITACIÓN EN LA DETERMINACIÓN DE LA BASE REGULADORA DE LAS PRESTACIONES, EN LOS SUPUESTOS DE EXONERACIÓN DE COTIZACIONES SOCIALES}

Los artículos 11 (a través de la introducción de un nuevo artículo 112.bis LGSS) y 13 de RDLJ prevén una exoneración de cotizaciones, aplicable tanto a las aportaciones empresariales, como a las de los trabajadores, en el supuesto de trabajadores por cuenta ajena, así como de las cotizaciones en el Régimen de Autónomos, por todas las prestaciones derivadas de contingencias comunes, salvo la correspondiente a incapacidad temporal.

Esta exoneración de cotizaciones está limitada a los supuestos en que el trabajador tenga 65 años o más años de edad y acredite un período de cotización de 35 o más años.

Para evitar subidas artificiales de las bases de cotización, en los supuestos de exoneración de cotizaciones citados, con su efecto en el cálculo de las prestaciones, el artículo 12 RDLJ (mediante la inclusión de un nuevo apartado 6 en el artículo 162 LGSS) limita las bases de cotización, a partir del período de exoneración, que hayan de tenerse en cuenta a efectos del cálculo de la base reguladora de las prestaciones derivadas de contingencias comunes y a las que alcance la exoneración (es decir, todas las prestaciones, salvo la incapacidad temporal). 
En el supuesto, y para la determinación de la base reguladora de las prestaciones, se limitan las bases de cotización del período de exoneración, en el sentido de que no pueden superar la cantidad resultante de incrementar el promedio de las bases de cotización del año natural inmediato anterior en el porcentaje de variación media conocida del IPC en el último año indicado.

Por lo que respecta a los trabajadores por cuenta propia, que tengan 65 años y 35 de cotización, el artículo 13.2 RDLJ prevé una exoneración de cotizaciones por todas las contingencias comunes, salvo la IT, previendo unas limitaciones similares en la consideración de las bases de cotización, por los períodos exentos de cotizar, a efectos de la determinación de la base reguladora de las prestaciones.

\section{Criterios provisionales de aplicación de las novedades a que se refiere el apartado I}

Respecto de las modificaciones normativas que se han comentado previamente, algunas entran en vigor el 1 de enero de 2002 de forma directa, mientras que otras precisan de la aprobación de las disposiciones reglamentarias para su entrada en vigor.

Por ello, en los apartados siguientes, se efectúan unos criterios provisionales de aplicación de aquellos preceptos contenidos en las disposiciones comentadas, cuya entrada en vigor, en toda su plenitud, se ha producido en fecha 1 de enero de 2002.

\section{Extinción de la incapacidad temporal por incomparecencia injustificada a efectuar los reconocimientos médicos}

En los supuestos en que, notificada a un beneficiario de la prestación de IT la obligación de someterse a un reconocimiento médico, si el mismo no comparece o no justifica la incomparecencia, se procederá a la suspensión cautelar en el percibo de la prestación, advirtiendo al interesado para que, en el plazo improrrogable de 10 días siguientes a la notificación, acredite la justificación de la incomparecencia.

Transcurrido dicho plazo sin acreditar causa de justificación a la incomparecencia o, cuando las alegaciones del interesado no fueran suficientes para justificar aquella, se procederá a la extinción de la prestación, con efectos del día siguiente a aquél en que debió efectuarse el oportuno reconocimiento médico. 


\section{Expedición de altas médicas en los procesos de IT}

Dado el nuevo contenido del artículo 131.bis.1 LGSS, no procede la expedición de altas médicas en los procesos de IT, a los exclusivos efectos de las prestaciones económicas de la Seguridad Social, quedando sin efecto, en consecuencia, el contenido del Real Decreto 1.117/1998, de 5 de junio, así como la Orden del Ministerio de Trabajo y Asuntos Sociales, 18 de septiembre de 1998, en lo que se refiere a dicha cuestión.

Por ello, cuando, como consecuencia de los reconocimientos y exámenes médicos practicados a los beneficiarios de las prestaciones de IT, por los servicios médicos adscritos a la Dirección Provincial correspondiente, se considere que el interesado ya no se encuentra en la situación de incapacidad, procederá, en todo caso, formular ante el respectivo Servicio de Salud propuesta de alta médica, en los términos previstos en el Real Decreto 575/1997, de 18 de abril, y en la Orden del Ministerio de Trabajo y Asuntos Sociales, de 19 de junio de 1997.

\section{Sanción con pérdida de la prestación con incomparecencia al reconocimiento médico}

Con independencia de lo previsto en el punto 2 anterior, la Dirección Provincial está facultada para sancionar con la pérdida de la prestación de IT, previa la tramitación del correspondiente expediente, la infracción consistente (artículo 25 LISOS) en no acudir, sin causa justificada, a reconocimiento médico.

Dada la facultad atribuida por el artículo 131.bis, la posibilidad sancionatoria señalada no deberá aplicarse directamente desde la Dirección Provincial salvo que se haya levantado acta por la Inspección de Trabajo y Seguridad Social, con la correspondiente tramitación del oportuno expediente sancionador, salvo que la prestación haya sido ya extinguida en aplicación del artículo 131.bis.1 LGSS.

\section{Prestación de IT que subsiste extinguido el contrato de trabajo}

El nuevo artículo 222.1 LGSS modifica, como se ha señalado, la regulación jurídica de la prestación de IT, en los supuestos en que, encontrándose el interesado en dicha situación, se le extingue su contrato de trabajo.

Para una clarificación del contenido y alcance del nuevo artículo 222.1 LGSS habrá de tenerse en cuenta lo siguiente: 


\section{a) AlCAnCe SubJetivo DE LA MOdificACióN}

La nueva regulación únicamente alcanza a los trabajadores por cuenta ajena, sin que la misma pueda extenderse a los trabajadores por cuenta propia.

Cuando se trate de los trabajadores señalados en último lugar, y los mismos estén percibiendo la prestación de IT, en el momento en que se cese en la actividad, los interesados seguirán percibiendo la prestación económica de la Seguridad Social hasta el momento en que se produzca una causa de extinción de la misma.

La nueva regulación alcanza a los supuestos de extinción del contrato de trabajo, cualquiera que sea la causa que origine la misma, que se produzcan a partir de 1 de enero de 2002, aunque, el proceso de IT se haya iniciado con anterioridad.

Por ello, cuando estando el trabajador en IT, se encuentra en alguna de las situaciones a que se refieren los párrafos 2 y 3 del artículo 208.1 LGSS se mantendría la regulación que se venía aplicando antes de $1 .^{\circ}$ de enero de 2002. Igual regulación se aplicará en el caso de los trabajadores fijos-discontinuos, a que se refiere el apartado 1.4 de dicho artículo.

En consecuencia, la nueva regulación alcanzará a todos los trabajadores por cuenta ajena (cualquiera que sea el Régimen en que estén encuadrados, salvo los incluidos en el Régimen de Empleados de Hogar) con independencia de que en el ámbito de la acción protectora se incluya o no el derecho a la prestación por desempleo y al margen de que reúnan o no los requisitos para el acceso a dicha prestación.

La nueva regulación se aplicará únicamente a los procesos de IT, en los que la extinción del contrato de trabajo se produzca a partir de 1 de enero de 2002, aunque, el proceso de IT se haya iniciado con anterioridad.

\section{b) Cuantía de la PRESTACióN}

Una vez que el INSS tenga conocimiento de la extinción del contrato de trabajo, y con efectos desde el día siguiente a la fecha de aquella, se procederá a modificar la cuantía de la prestación de IT, de modo siguiente:

Siempre que el interesado, en el ámbito de la acción protectora, tenga derecho a desempleo, con independencia de que reúna o no los requisitos para acceder a la respectiva prestación contributiva, la base reguladora pasará a ser el promedio de las bases de cotización por contingencias profesionales, excluidos los conceptos por horas extraordinarias, correspondiente a los 180 días anteriores a la extinción del contrato. 
En el supuesto de que el trabajador no tenga derecho a desempleo, en el ámbito de la acción protectora, la base reguladora será equivalente al promedio de las bases de cotización por contingencias profesionales, excluidos los conceptos por horas extraordinarias, correspondientes al período de 180 días anteriores al hecho causante de la prestación.

En el caso de que el trabajador alegase un derecho de desempleo anterior (que estaba suspendido) la Dirección Provincial efectuará comunicación al Instituto Nacional de Empleo, con la finalidad de que por dicho Organismo se certifique la base reguladora de la prestación por desempleo.

El porcentaje pasará a ser el $70 \%$ durante los 180 días siguientes al de la extinción del contrato de trabajo. Agotados los 180 días señalados, el porcentaje será del $60 \%$.

Lo anterior se entiende sin perjuicio de que el interesado alegue la reanudación de un derecho anterior suspendido. En estos casos, la Dirección Provincial procederá a efectuar comunicación al INEM, en orden a que por dicho Organismo se certifique el porcentaje aplicable sobre la base reguladora correspondiente al derecho que se reabre.

En todo caso, deben tenerse en cuenta los topes de la prestación de desempleo contenidos en el artículo 211.3 LGSS y en el artículo 4.4 del Real Decreto 625/1985, de 2 de abril, sobre prestación de desempleo.

Los indicados topes son:

- $170 \%$ del salario mínimo interprofesional (SMI), cuando el trabajador no tenga ningún hijo a cargo.

$-195 \%$, cuando tenga un hijo.

- 220\%, cuando tenga dos o más hijos.

A tales efectos, se entiende que se tienen hijos a cargo cuando estos sean menores de 26 años o mayores incapacitados, carezcan de renta de cualquier naturaleza superiores al SMI y convivan con el beneficiario.

\section{Prestación de IT causada desde la situación de desempleo}

El apartado tercero del artículo 222 LGSS modifica la regulación de la prestación de IT, en los casos en que se cause la misma desde la situación de desempleo, si bien la regulación difiere sustancialmente según que el proceso de IT sea una recaída de otro anterior iniciado antes de la extinción del contrato de trabajo o, por contrario, constituya un nuevo proceso.

Las reglas que se indican a continuación se aplicarán a los procesos de IT, causados desde la situación de desempleo, en los que el agota- 
miento del período de percepción de desempleo se produzca a partir de $1 .^{\circ}$ de enero de 2002, aunque el correspondiente proceso de IT se haya iniciado con anterioridad.

\section{a) RECAÍDA DE UN PROCESO ANTERIOR}

En este caso, la regulación contenida en la LAC no modifica sustancialmente la anterior, salvo en lo que se refiere a la cuantía de la prestación, una vez que agote el período de desempleo, ya que a partir de dicha fecha la prestación de IT se sigue percibiendo en la cuantía de desempleo y no mediante la aplicación de las reglas propias de la IT, como sucedía con anterioridad.

La nueva regulación se aplicará a los procesos de IT, en los que el agotamiento en el período de percepción de desempleo se produzca a partir de 1 de enero de 2002, con independencia de la fecha en que se iniciaron aquellos.

\section{b) NueVo PROCESO IT}

En el supuesto, si bien durante el período en que el desempleado percibe la IT directamente del INEM la regulación anterior no sufre modificación, sin embargo se produce una alteración sustancial, desde el momento en que el trabajador pasa a recibir la prestación directamente de la Dirección Provincial del INSS, por haberse agotado el período de prestación de desempleo.

A partir de la fecha indicada, deberá modificarse la cuantía de la prestación de IT, que pasará a ser del 75\% del salario mínimo interprofesional, excluida la parte proporcional de pagas extraordinarias, es decir, que el importe diario de la prestación de IT, en los supuestos referidos, será, en el 2002 y conforme a las previsiones contenidas en el Real Decreto 1.466/2001, de 27 de diciembre, 11,06 euros/día.

La nueva regulación se aplicará a los procesos de IT, en los que el agotamiento en el período de percepción de desempleo se produzca a partir de 1 de enero de 2002, con independencia de la fecha en que se iniciaron aquellos.

\section{Jubilación parcial}

En el ámbito de la jubilación parcial las modificaciones introducidas no alteran, en principio, los criterios que se vienen aplicando. Por ello, entre tanto se promulguen las normas reglamentarias a que alude 
el artículo 166.4 LGSS (en la redacción dada por el artículo 2 RDLJ) se seguirán aplicando los criterios en vigor.

7. Compatibilidad entre el percibo de la jubilación y la realización de un trabajo a tiempo parcial

Como se ha indicado en el apartado $1.4 \mathrm{c}$ ), el artículo 1 RDLJ prevé la posibilidad de que una persona que venga percibiendo la pensión de jubilación pueda compatibilizar el percibo de la misma con la realización de un trabajo a tiempo parcial, si bien con la reducción proporcional de importe de la pensión.

No obstante, hay que advertir que la regulación de la compatibilidad señalada queda condicionada a los términos que reglamentariamente se establezcan, por lo que hasta que no entren en vigor las disposiciones reglamentarias oportunas se deberá seguir aplicando en su integridad lo establecido en el artículo 161 LGSS, así como en el artículo 16 de la Orden del entonces Ministerio de Trabajo de 18 de enero de 1967, sobre pensión de jubilación en el Régimen General de la Seguridad Social.

\section{Prestaciones de muerte y supervivencia}

El RDMS contiene de forma detallada la nueva regulación aplicable a dichas prestaciones, sin que sea preciso el dictado de instrucciones provisionales, en tanto se procede a la adecuación y modificación de la Circular 3/1998.

No obstante, se hace las siguientes advertencias:

\section{a) LÍMITE DE LAS PENSIONES DE VIUDEDAD Y ORFANDAD DERIVADAS DE UN MISMO CAUSANTE}

El artículo 1.4 RDMS prevé que la suma de las pensiones de viudedad y orfandad, derivadas de un mismo causante no podrán superar el límite de $100 \%$ de la base reguladora (artículo 179.4 LGSS).

Dicho límite operará respecto de las pensiones que se causen a partir del 1 de enero de 2002, de manera que, durante dicho ejercicio y por lo que se refiere a las pensiones citadas, la suma de las pensiones de orfandad que concurran con una pensión de viudedad no podrán superar nunca el $54 \%$ de la base reguladora, o del $30 \%$ (en el supuesto de que 
concurran con una pensión de viudedad calculada con el $70 \%$ de la base reguladora).

Sin embargo, por lo que se refiere a las pensiones causadas, con anterioridad al 1 de enero de 2002, la modificación de la pensión de viudedad no alterará, en modo alguno, la cuantía de las pensiones de orfandad, derivadas del mismo causante.

\section{b) APLICACIÓN DE LA NO EXTINCIÓN DE LA PENSIÓN DE VIUDEDAD POR NUEVO MATRIMONIO DEL PENSIONISTA}

El artículo 2 RDMS establece los requisitos para que la pensión de viudedad no se extinga, aunque el preceptor de la misma contraiga nuevo matrimonio.

Esta nueva regulación se aplicará exclusivamente a las pensiones que se estén percibiendo el 1 de enero de 2002, o que, aún no percibiéndose en dicha fecha, estuviesen suspendidas, pero sin que pueda ser aplicada a los pensionistas cuya pensión de viudedad fue extinguida, por cualquiera de las causas previstas en el ordenamiento vigente, antes de la entrada en vigor de la LAC, es decir, el 1 de enero de 2002.

\section{Adopción de medidas cautelares}

La nueva Disposición adicional 17.bis LGSS posibilita a la Entidad Gestora para que pueda adoptar medias cautelares cuando los beneficiarios no presenten, en el plazo establecido, los documentos, declaraciones o datos, a que vengan obligados, y que puedan afectar al mantenimiento del correspondiente derecho.

En tal sentido, cuando fijada en norma expresa, no sólo la obligación de presentar el documento, la declaración o dato correspondiente, sino también el plazo para ello (por ejemplo, las declaraciones de ingresos a efectos de complementos a mínimos), transcurrido dicho plazo, sin que el interesado haya cumplido la citada obligación, la Dirección Provincial procederá a efectuar notificación al interesado para que presente dicha declaración, documento o dato en el plazo improrrogable de 10 días, adviertiéndole que, en caso contrario, se procederá a la suspensión cautelar de la prestación.

De adoptar la medida, la suspensión tendrá efectos desde el día siguiente al que finalizó el primer plazo de presentación de la declaración, documento o dato. Una vez que por el interesado se presente la declaración, documento o dato se repondrá el percibo de la prestación 
(si se mantienen los requisitos para ello) desde la fecha en que tuvo efectos la suspensión.

Cuando exista en la norma la obligación de presentar el documento, declaración o dato, sin que esté fijado el plazo para ello, en la notificación que realice la Dirección Provincial, se le advertirá directamente al interesado sobre la suspensión cautelar de la prestación, desde el día siguiente al que finalice el indicado plazo, en el supuesto de que no presente los documentos, declaraciones o datos respectivos.

Una vez que por el interesado se presente la declaración, documento o dato, se repondrá el percibo de la prestación (si se mantienen los requisitos para ello) desde la fecha en que tuvo efectos la suspensión.

\section{Normas procedimentales}

Las Normas procedimentales contenidas en la LAC (nueva Disposición Adicional 25 LGSS y nueva redacción del artículo 71 LPL) en nada altera los criterios que se venían aplicando respecto a las materias contenidas en dichos preceptos salvo en las dos cuestiones que a continuación se señalan:

a) El plazo para contestar la reclamación previa es de 45 días a partir de la formulación de la misma.

b) Excepcionalmente, pueden caber supuestos en los que, ante la Dirección Provincial, se puedan presentar reclamaciones previas contra las resoluciones expresas o presuntas dictadas por las Mutuas a tenor de lo establecido en el párrafo $2 .^{\circ}$, apartado 2, del artículo 71 LPL.

El único supuesto incluido en las previsiones del artículo citado en último lugar, es el de la negativa de la Mutua, de forma expresa o presunta, a reconocer una prestación de IT derivada de contingencias profesionales o el supuesto en que, reconocida por la Mutua una prestación de IT derivada de contingencias comunes, el interesado alegue que la causa originaria de la situación de IT es una contingencia profesional.

En estos casos, si se formulase reclamación previa ante la Dirección Provincial del INSS, contra una resolución expresa o tácita de la Mutua, se procederá a solicitar informe a la Entidad colaboradora, así como el expediente que dio lugar a la resolución recurrida, decidiendo la Dirección Provincial la contingencia de la que deriva la prestación y 
comunicando su resolución, tanto al interesado como a la Mutua, a fin de que por ésta puedan ejercerse las acciones que se estimen convenientes.

\section{Cuantía de la pensión en los supuestos de jubilación anticipada por aplicación de derecho transitorio}

El RDLJ, en su artículo 4, ha modificado los porcentajes reductores de la cuantía de la pensión, en los supuestos de acceso a la misma, en virtud de lo dispuesto en la Disposición Transitoria 3. ${ }^{a}$ LGSS.

En este ámbito se seguirán aplicando los criterios dictados hasta el momento, si bien teniendo en cuenta que frente a la regulación anterior (en las que existían únicamente 2 coeficientes reductores, según cuál fuese la forma de acceso a la pensión) en la regulación vigente a partir de 1 de enero de 2002, los coeficientes se diferencian según la forma de acceso a la pensión de jubilación y el período cotizado.

Si el trabajador accede a la pensión de jubilación y el acceso a la misma se debe a causa imputable al mismo, el coeficiente sería siempre el $8 \%$.

Si el trabajador accede a la jubilación y la relación laboral previa se ha extinguido por las causas previstas en la Disposición Transitoria 2. ${ }^{a} .2$.a) del Real Decreto 1647/1997, de 30 de octubre, o en los supuestos del apartado 3 de dicha Disposición Transitoria, el coeficiente será, según cual sea el período cotizado, el siguiente:

- Con 30 o menos años: el 8\%.

- Con 31 a 34 años cotizados, ambos inclusive: 7,5\%.

- Con 35 a 37 años cotizados, ambos inclusive: $7 \%$.

- Con 38 ó 39 años cotizados, ambos inclusive: 6,5\%.

- Con 40 o más años cotizados: $6 \%$.

\section{Nuevo mecanismo de jubilación anticipada con minoración de la cuantía de la pensión}

Como se ha indicado, el artículo 3 RDLJ (a través de la modificación del artículo 161 LGSS) establece la posibilidad de jubilación anticipada a partir de los 61 años, con independencia de que el interesado tuviese o no la condición de mutualista antes de 1 de enero de 1967, siempre que se cumplan los requisitos que se han señalado en el apartado I anterior. 
Por ello, la posibilidad de que se pueda acceder a la jubilación anticipada, requiere la acreditación de los siguientes requisitos:

- Tener una edad mínima de 61 años.

- Tener acreditados 30 años de cotización, sin computar la parte proporcional de pagas extras.

- Estar inscrito como demandante de empleo y haberlo estado durante un período de, al menos 6 meses antes de la solicitud de la pensión.

- Que el cese en el trabajo, como consecuencia de la extinción del contrato de trabajo, no se haya producido por causa imputable a la libre voluntad del trabajo.

Para la acreditación de este último requisito se aplicará, en tanto no se aprueben las oportunas disposiciones reglamentarias, las previsiones contenidas en los apartados 2 y 3 de la Disposición Transitoria 2. ${ }^{a}$, del Real Decreto 1.647/1997, así como, en lo que resulte de aplicación la Circular de este Instituto 3/98.

La cuantía de la pensión se minorará aplicando el porcentaje que se señala, en función de los años que falten al trabajador para cumplir los 65 años, así como el período de cotización que tenga acreditado, del modo siguiente:

- Con 30 o menos años: $8 \%$.

- Con 31 a 34 años cotizados, ambos inclusive: 7,5\%.

- Con 35 a 37 años cotizados, ambos inclusive: $7 \%$.

- Con 38 o 39 años cotizados, ambos inclusive: $6,5 \%$.

- Con 40 o más años cotizados: $6 \%$.

\section{Cuantía de la pensión cuando se accede a la misma con más} de 65 años

El artículo 10 RDLJ incorpora un nuevo apartado 2 en el artículo 163 LGSS, posibilitando que, en determinados supuestos, el porcentaje aplicable a la base reguladora de la pensión de jubilación pueda superar el 100\%.

Los supuestos en los que cabe tal posibilidad son los de acceso a la pensión acreditando 35 años de cotización, y a una edad de 66 o más años.

Para la aplicación de lo establecido en el nuevo artículo 163 LGSS, se aplicará lo siguiente:

a) Sobre la base reguladora de la pensión se aplicará la escala de coeficientes a que se refiere el apartado $1 .^{\circ}$ del artículo 163 LGSS. 
b) Si el interesado acredita 35 años de cotización en la fecha del cumplimiento de los 65 años, se añadirá un $2 \%$ por cada año cotizado en que se acceda a la jubilación más allá de los 65 años. Por ejemplo, si el trabajador acredita, en el cumplimiento de los 65 años de edad, 35 de cotización y accede a la pensión a los 66 años, el porcentaje aplicable a la base reguladora sería el 102\%; si en el mismo supuesto se accede a la pensión a los 67 años de edad, el porcentaje sería el $104 \%$.

c) Si en el cumplimiento de los 6 años no se acreditan 35 años de cotización, el porcentaje adicional se aplicará a partir de la fecha en que se cumpla dicho período.

Por ejemplo, el supuesto de un trabajador que en la fecha del cumplimiento de los 65 años de edad, acredita 34 años de cotización. A los 66 años, acreditará 35 años de cotización, el 2\% adicional se aplicará por cada año cotizado que transcurra desde que se acrediten los 35 años de cotización; es decir, en este ejemplo, se tendría derecho al $102 \%$ si se accede a la jubilación a los 67 años.

En ningún caso la cuantía de la pensión obtenida (incluso con un porcentaje de base reguladora superior al 100\%) podrá ser superior al importe que, en cada momento, esté vigente, como tope de percepción de pensión pública.

\section{Subsidio asistencial de desempleo para mayores de 52 años}

El artículo 5 RDLJ modifica el artículo 216.3 LGSS, en el sentido de extender la vigencia del subsidio asistencial de desempleo para trabajadores con 52 o más años, que reúnan todos los requisitos, salvo la edad, para acceder a la pensión de jubilación, hasta la fecha en que, en cada caso, se tenga derecho a la pensión ordinaria de jubilación.

Por ello, deberá variarse el sentido de la certificación que se viene realizando, con destino al INEM, en los supuestos señalados, eliminando la referencia a la posibilidad del trabajador de jubilarse a los 60 años, por aplicación de derecho transitorio.

Por el contrario, la certificación del INSS acreditará la fecha en que el trabajador cumple los 65 años de edad, o aquélla en la que el interesado puede jubilarse, antes del cumplimiento de dicha edad, por pertenecer a colectivos a los que les son de aplicación los coeficientes reductores de la edad de jubilación, o de aquellos a los que la normativa especifica establece, como edad ordinaria de jubilación, una inferior a los 65 años. 


\section{Incapacidad permanente}

A partir del 1 de enero de 2002 debe entenderse modificado, por aplicación del nuevo contenido de los artículos 138.1 y 139.5 , ambos de la LGSS, el artículo 6 del R.D. 164/1997, de 31 de octubre, de desarrollo de la Ley 24/1997, de 15 de julio, así como la Circular de este Instituto 3/1998, todo ello en el siguiente sentido:

a) Se admitirá el acceso a la prestación de incapacidad permanente, en el grado que corresponda, aunque el solicitante tenga 65 años en la fecha del hecho causante, si la contingencia de la que deriva la incapacidad permanente, es un accidente de trabajo o una enfermedad profesional.

b) Por lo que se refiere a las pensiones de incapacidad permanente, derivadas de contingencias comunes, cuando el interesado tenga, en la fecha del hecho causante, 65 o más años de edad y no reúna los requisitos exigidos para acceder a la pensión de jubilación, se actuará del siguiente modo:

- Se procederá a la calificación de la situación de incapacidad en el grado que corresponda.

- Se determinará la base reguladora de la pensión, aplicando las normas vigentes.

- Por último, sobre la base reguladora no se aplicará el porcentaje que corresponda, con carácter general, al grado de incapacidad reconocido, sino el del $50 \%$.

Este último porcentaje se aplicará en todos los grados de incapacidad permanente reconocidos incluso en el correspondiente a la gran invalidez.

16. Determinación de la base reguladora de las prestaciones económicas, en los supuestos y por los períodos en que el interesado esté exonerado de cotizar

Los artículos 11 y 13 RDLJ prevén que, en determinados supuestos, exista la exoneración de cotizaciones sociales por contingencias comunes, salvo la IT cuando el trabajador tenga 65 o más años de edad y acredite un período de cotización mínimo de 35 años, en el momento del cumplimiento de la edad indicada, o en otro posterior.

A su vez el artículo 162.6 LGSS (incorporado por el artículo 12 RDLJ) así como el apartado 2 del artículo 13 del citado RDLJ prevé 
determinadas limitaciones en el cálculo de la base reguladora de las prestaciones a que alcance la exoneración.

Para la aplicación de tales limitaciones, se actuará del siguiente modo:

a) Las limitaciones en las bases de cotización a tener en cuenta en la respectiva base reguladora alcanzan a todas las prestaciones económicas por contingencias comunes, salvo la de IT.

b) Las limitaciones indicadas únicamente serán por los períodos a partir de los cuales opera la exoneración de cotizaciones.

c) En los supuestos indicados por los supuestos señalados, a efectos de la determinación de la base reguladora se aplicará lo siguiente:

- Trabajadores por cuenta ajena:

- A partir de la fecha de la exoneración, se tomarán en principio las bases por las que haya venido cotizando el interesado, siempre que su importe no exceda del límite que se indica en el párrafo siguiente.

- A efectos del límite indicado, la base de una mensualidad (correspondiente al período exento) no podrá ser superior al resultado de incrementar el promedio de las bases de cotización del año natural inmediatamente anterior, en el porcentaje de variación del IPC correspondiente a este último año.

Por ejemplo, si la exoneración de cuotas se iniciase a partir del 1 de julio de 2002, la base de cotización de ese mes no podría ser superior al resultado de incrementar el promedio de las bases de cotización del ejercicio 2001, en el porcentaje de variación del IPC en este último año (período enero-diciembre).

- Trabajadores por cuenta propia:

A efectos de la determinación de la base reguladora de las prestaciones a las que alcance la exoneración de cuotas, se aplicarán las reglas establecidas para los trabajadores por cuenta ajena. 